\title{
Research on the Contribution of Female Human Capital in Economic Growth in Guangdong Province
}

\author{
Langhua Guan \\ Jinan University, Guangzhou, China \\ Email: sglanghua@126.com
}

How to cite this paper: Guan, L.H. (2019) Research on the Contribution of Female Human Capital in Economic Growth in Guangdong Province. Modern Economy, 10, 1271-1291.

https://doi.org/10.4236/me.2019.104087

Received: March 15, 2019

Accepted: April 20, 2019

Published: April 23, 2019

Copyright () 2019 by author(s) and Scientific Research Publishing Inc. This work is licensed under the Creative Commons Attribution International License (CC BY 4.0).

http://creativecommons.org/licenses/by/4.0/

\begin{abstract}
This paper uses the statistical data from 1997 to 2015 to calculate the female human capital stock in Guangdong Province, and empirically analyzes the contribution rate of female human capital to Guangdong's output and its comparison with men. At the same time, it empirically analyzes the contribution of female human capital stocks at different levels to Guangdong's economic growth, studies the correlation between women's education levels and economic growth, and examines the differences in the impact of male and female human capital on economic growth. The research results show that female human capital is an important factor affecting Guangdong's economic growth. Male human capital has a greater impact than female human capital. Female human capital at different educational levels has different effects on economic growth. In order to promote economic and social development, we should increase the awareness of gender equality and strengthen the attention and investment in women's human capital.
\end{abstract}

\section{Keywords}

Female Human Capital, Economic Growth, Per Capita Education Years

\section{Introduction and Literature Review}

\subsection{Introduction of Research Background}

Human Capital, also known as "intangible capital," is opposed to "material capital." Different from material capital, human capital is based on human beings and objects, attached to the individual labor force, and does not transfer with the individual's selling. It is a kind of capital existing in the individual, such as 
knowledge and skills, cultural and technical level and health status. The formation and accumulation of human capital is mainly formed by the labor force's own human investment, such as receiving education, maintaining its own bodily functions, and freely flowing expenditures at home and abroad. The most important part of the formation of human capital is the labor expenditure of the labor force. Through a certain amount of education expenditure, the formation of educational capital improves the quality of the labor force, the working ability of the labor force and the level of technology, thereby improving the labor productivity of the whole society.

Human capital can be traced back to Plato's "Utopia”. In this work, Plato profoundly discusses the important economic value of the two elements of education and training. The first officially regarding the labor force as a kind of capital is Adam Smith. In the "The Wealth of Nations", Smith proposed that the professional division of labor can promote the improvement of labor productivity, and the professional division of labor, the proficiency of labor skills, and its judgment. The strength of ability puts forward higher requirements. Because the proficiency level of labor skills can be improved through education and training, and education and training take time and tuition. Therefore, the accumulation of human capital is formed by investment in human resources. In Marx's theory of labor value, human labor is divided into complex labor and simple labor. The former has higher value and is more than simple labor. Therefore, Marx will be able to improve the science and technology of human intelligence and skills. It was seen as an important source of social productivity. The modern "father of human capital", Schultz, the 1979 Nobel laureate in economics, gave a systematic exposition of human capital theory in a speech at the 1960 American Economic Conference, and further studied human resources. He also makes a further study about the ways and means of human capital formation, and makes a quantitative study on the return on investment in education and the contribution of education to economic growth.

In the process of social and economic activities, individuals continue to invest a large number of resources into production to produce various commodities suitable for market demand; on the other hand, individuals develop and improve people through various forms, such as intelligence, physical strength and moral quality, in order to form a higher production capacity. Human capital theory equates the formation mechanism of human productive capacity with the formation mechanism of physical capital, and advocates human capital as a kind of capital attached to human beings-for example, the sum of various production knowledge and skill stocks. The study of human capital theory has lifted the prohibition of "capital is only physical capital" in traditional economic theory. By dividing capital into two major sectors, human capital and physical capital, a new perspective on the theory and practice of research economics has been created. 


\subsection{Introduction of Literature Review}

Modern economic growth theory holds that economic growth is the foundation of social development, and human capital is the endogenous factor and driving force of economic growth [1]. Women are the creators of social material wealth, spiritual wealth and human resources. In modern society, as women become more and more involved in social productive labor, female human capital plays an increasingly important role in economic growth and social development. The increase in female human capital stock will inevitably promote a sustainable socio-economic development and a shift in economic growth. Due to the influence of traditional human capital theory on the homogeneity assumptions of laborers, the results of human capital research specifically for female groups are few. In 2003, Professor Pan Jinxi [2] first proposed the concept of gender human capital, which provided a strong theoretical support for the further study of female human capital in the academic circle. Since then, research on women's human capital has gradually increased. In the study of the relationship between female human capital and economic growth, China's Gender Equality and Women's Development Assessment Report pointed out that 2/3 of the provincial and municipal women's health indicators in 2004 were highly correlated with per capita GDP. Sun Jian [3] and other studies found that the number of female illiterate and primary school students in the eastern part of China decreased, the number of junior high school and high school education population increased, and both were positively correlated with economic development; in the central and western regions, female illiterate and primary school. The decrease in the educational population and the increase in the high school population have a positive correlation between female human capital and economic development. Wei Jifei, Li Lutang, and Su Zhitu [4] proposed that the stock and quality of rural women's human capital are relatively low, which has seriously affected the sustainable development of rural economy and rural talents, and it is necessary to increase investment in rural education. Guo Qingwang and Jia Junxue [5] constructed a two-stage human capital accumulation model including basic education and higher education, and examined the scale, structure and accessibility of public education expenditures. The human capital investment behavior of families with different educational backgrounds is skilled and unskilled. The relative supply of labor and the impact of relative efficiency reveal the impact of public education policies on economic growth and human capital premium. Zhang Yu [6] used annual data to conduct empirical tests. The research found that female human capital is positively related to economic growth, but female human capital generated by education must accumulate to a certain level (junior high school education and above) to the economy. The growth has a significant positive impact, and the coefficient of promotion of female human capital variables in the central and western regions to economic growth is greater than that in the eastern region. Sun Jialu et al. [7] used China's provincial panel data from 1997 to 2010 to examine the role of human capital in economic growth. The regression results 
show that both human health and education have both economic growth and per capita economic growth. It has played a positive role in promoting and the elasticity of healthy human capital investment is more significant. Hu Zongju [8] used panel data models and methods from 31 provinces in China from 2003 to 2012 to examine the differences in the impact of male and female human capital on economic growth. The results show that human capital is an important factor affecting economic growth and the impact of male human capital. Human capital is an important factor affecting economic growth, and the impact of male human capital is greater than that of female human capital.

The main domestic research results show that the results of human capital research for female groups are rare. Existing research generally believes that female human capital is strongly related to economic growth, and male human capital has greater impact on economic growth than female human capital. In addition, the overall level of female human capital is low, especially the rural women's human capital level is in urgent need of improvement. However, there is not much research on female human capital in provincial regions. Research on the relationship between female human capital and Guangdong's economic growth is almost in a blank state. These studies are all analyzed from the perspective of the overall human capital of a country or region. Without further research on human capital, it is difficult to analyze the role of human capital components in economic development in detail.

Guangdong Province is China's most populous province. The total population, the total employed population and the total female employment population rank first in the country. Female human capital plays an important role in the rapid economic growth of Guangdong Province. Capital has different effects on economic growth. This paper makes an empirical analysis of this. The main work of this paper is to calculate the female human capital stock in Guangdong Province, and empirically analyze the contribution rate of female human capital to Guangdong's output and its comparison with males. At the same time, it empirically analyzes the contribution of female human capital stocks at different levels to the economic growth of Guangdong Province, and studies the correlation between women's education levels at all levels and economic growth. The content discussed in this paper, on the one hand, extends the discussion of human capital theory to a more detailed level of female human capital, which is conducive to enriching the theoretical research of female human capital. On the other hand, we make a correct understanding of women and give full attention to women's values, and provide a basis for eliminating barriers to increasing female human capital investment and female human capital stock. At the same time, in the context of China's transformation of economic growth mode and the path of new industrialization, increasing the accumulation of female human capital is of great significance for promoting the comprehensive development and transformation and upgrading of the economy and society. This paper hopes to arouse the understanding of the importance of women's human capital investment and promote effective measures to improve women's human capital. 


\subsection{Structure of This Paper}

The structure of this paper is organized as follows:

The first chapter, the research background. This chapter highlights the research significance of this paper by describing the relevant research background.

The second chapter, literature studies and reviews. This chapter will introduce the research literature related to human capital and economic growth at home and abroad, and review and highlight the key points of this paper.

The third chapter is about the discussion of human capital. This chapter will introduce the development of human capital theory and related measurement methods, focusing on the measurement methods of this paper, the average years of education, and using this method to measure the human capital stock of Guangdong Province over the years, and to carry out the human capital stock of Guangdong Province over the years. analysis.

The fourth chapter, empirical analysis. This chapter will establish a model of human capital and economic growth, and use the data to fit the model to obtain relevant empirical results.

The fifth chapter analyzes the empirical results. Through the above empirical evidence, this paper analyzes the relevant results and proposes corresponding policy opinions.

\section{Analysis of the Stock and Current Situation of Female Human Capital in Guangdong Province}

\subsection{Human Capital Stock Measure}

For the measurement of human capital, since it cannot be directly measured like material capital, all scholars currently measure the human capital in an indirect way. Based on the research of domestic and foreign scholars, the measurement of human capital mainly includes the following categories: the lifetime income method based on income perspective, the comprehensive index method based on multiple indicators, and the education years based on education.

\subsubsection{Lifetime Income Method}

The Lifetime Income Method is based on the measurement of human capital by income. From the perspective of income, each person's life is divided into five stages, and the sum of the present values of income at different stages is calculated, and the sum is the human capital stock. To sum up, the sum is the human capital stock, which is a relatively simple human capital estimation method. The formula is:

$$
H_{x}=\sum_{i=x}^{\infty} \frac{S_{x, i}\left(\delta_{i} \tau_{i}-C_{i}\right)}{1+d}
$$

Among them, $H$ represents the present value of the labor personal income of the current age $x$, and $d$ is the discount rate, which is usually expressed by the 
market interest rate, which represents the human capital of the labor. $S$ represents the probability that a person of age $x$ survives to $i$ years old, $\delta$ represents the labor force employment rate of age $i, \tau$ is represented by the income level of the labor force of age $i$, and $C$ represents their living expenses. Since the method can use the market interest rate as the discount rate, and does not need to assume the depreciation rate of the assumed human capital, the calculation is relatively simple. However, because of the heterogeneity of income caused by labor investment, that is, the heterogeneity of human capital, many scholars have not used this method to estimate human capital.

\subsubsection{Comprehensive Indicator Method}

The comprehensive indicator method considers from a broader perspective and integrates education, work experience, and health indicators into the calculation range of human capital stock. This method mainly considers human capital from various aspects. In addition to economic factors and physiological indicators, the calculation method is relatively mature. However, due to the lack of a unified standard, the various scholars often use different analysis indicators, which leads to differences in their respective measurement systems, which leads to great differences in calculation results. Therefore, although the method does not require assumptions about the discount rate and does not require depreciation of human capital compared to the income method, it is difficult to empirically lack due to the lack of uniform standards.

\subsubsection{Educational Indicator Method}

The Education Indicators Method is the only one of these methods that has a uniform standard. Since education is a very important factor in promoting the growth of human capital, the estimation of human capital from the perspective of education has its innate scientific and rationality. Different from the income method and the comprehensive index method, the education law is based on the degree of education of the labor force, and the education index method and the years of education are often used.

The Education Indicators Act is measured by relevant indicators of education, such as the number of teachers, the dropout or repetition rate of students, and the government's financial expenditure on education. In addition, some scholars appreciate the use of international test scores to measure human capital. However, this method is only an ideal and perfect method, but it has a lot of difficulties in practical operation. Therefore, scholars are more likely to adopt the method of education years.

This method firstly classifies the employed population according to the number of years of education or education, and then calculates the average years of education by weighting by time or level. By calculating the average number of years of education and the product of the employed population, it can be calculated. The total human capital stock of the year can be calculated. This method is not only simple and easy, but also has wide applicability in practice. Its outstand- 
ing features are: The number of years of education is positively correlated with human capital, and positively correlated with human capital accumulation and individual income.

Based on the above analysis, this paper adopts the method of average years of education. The calculation method is as follows: According to the education level, the active labor force in Guangdong Province is divided into seven stages: illiteracy, elementary school, junior high school, high school, junior college, undergraduate and graduate students. The education period of the stage is $N_{-} i=1$, $2,3, \cdots, 7$ (Table 1).

\subsection{The depreciation of Human Capital}

\subsubsection{Research on Depreciation of Human Capital}

In the face of the problem of depreciation of human capital, different scholars have different understandings in their respective research processes, which can be divided into three main areas:

First, ignore the depreciation effect of human capital. Some scholars ignored the depreciation of human capital directly when calculating the human capital. In order to simplify the discussion, directly ignore the depreciation of human capital.

Second, human capital should be value added rather than depreciated. Some scholars believe that human capital is endogenous. Therefore, the depreciation of human capital should depend on the diligence of human beings. Therefore, human capital should be value-added rather than depreciated. For example, Graham \& Webb [9] found that human capital is in a state of added value in the study of human capital in the United States, and thus indicates that other scholars' calculations underestimate the human capital stock, and they think that they use excessive human capital depreciation rate.

Third, human capital is the same as physical capital. With the progress of social science and the development of the times, especially the renewal of knowledge, with the extension of life expectancy, human capital will have a certain depreciation. This is the majority of scholars. This is the conclusion that most scholars agreed. Hou Fengyun, Fan Yubo et al. [10] divided the labor force into three stages in China's human capital stock estimation: human capital growth period of 1 - 44 years old, human capital decay period of 45 65 years old, and human resources after 65 years old. The capital is 0 . Therefore, the depreciation of human capital is calculated as the ratio of the growth period of 44 years to the decay period of human capital of 21 years old. This ratio is converted into the annual depreciation of human capital, which is allocated to the decay period of 21 years, which calculates the depreciation rate of human capital. It is $9.98 \%$. Similar calculations include Qian Xueya, Wang Qiushi, etc. [11], human capital Divided into general human capital and professional human capital, using the geometrically decreasing efficiency model, the depreciation rate of human capital is calculated to be approximately $5.14 \%$. 
Table 1. Education level and years of labor at all levels.

\begin{tabular}{cc}
\hline Labor education $Q_{i}, i=1,2, \cdots, 7$ & Years of education $N_{i}, i=1,2, \cdots, 7$ \\
Illiterate & 1.5 \\
Primary School & 6 \\
Junior High School & 9 \\
High school & 12 \\
College & 15 \\
Bachelor & 16 \\
Postgraduate & 19 \\
\hline
\end{tabular}

\subsubsection{Method on Depreciation of Human Capital}

In the discussion of human capital estimation, according to the practice of most scholars, the estimation of human capital is subject to certain depreciation treatment. According to Hou Fengyun's calculation method, the depreciation of human capital is divided into two parts, part is technical depreciation, part is physiological depreciation, and relevant adjustment according to actual situation.

First, the depreciation of human capital technology. According to the state's compulsory education regulations, school-age children aged 6 - 7 must be sent by their parents or guardians to complete compulsory education. Considering the influence of some backward areas, this paper assumes that the average age of nationals is 7 years old. According to the hypothesis, the human capital growth period of 7 - 44 years old, the human capital decay period of 45 - 65 years old, and the human capital after age 65 is 0 . Then, the labor human capital growth period is 38 years, the decay period is 21 years, and the calculation is available. The technical depreciation rate of human capital is $8.62 \%$, which is slightly lower than that of Hou Fengyun. This is because of the impact of the actual age of admission in China.

Second, the physical depreciation of human capital. The physiological depreciation of human capital is mainly based on the physiological condition of the labor force. Since part of the labor force may not be able to continue working in part due to part of the process, the proportion of this part is expressed by $\sigma$ to measure the physiological depreciation of human capital. Understand that it is impossible to continue working, retire early or die. For the sake of simple discussion, $\sigma$ is expressed by the natural mortality rate of the population over the years.

According to the above discussion, the calculated depreciation formula for human capital is:

$$
H_{t}=H_{t-1}(1-\sigma)(1-8.62 \%)
$$

\subsubsection{Differences in Educational Level between Male and Female Employees in Guangdong Province}

According to the 1998-2016 Labor Yearbook and the 1998-2016 Guangdong Statistical Yearbook, this paper analyzes the proportion of male and female em- 
ployees and education in Guangdong Province over the years as shown in Figure 1 and Table 2 and Table 3.

In Figure 1, the abscissa represents the year, the ordinate represents the proportion of employees, and Figure 1 shows the trend of the proportion of male and female employees in Guangdong Province from 1997 to 2015. In 1999, male

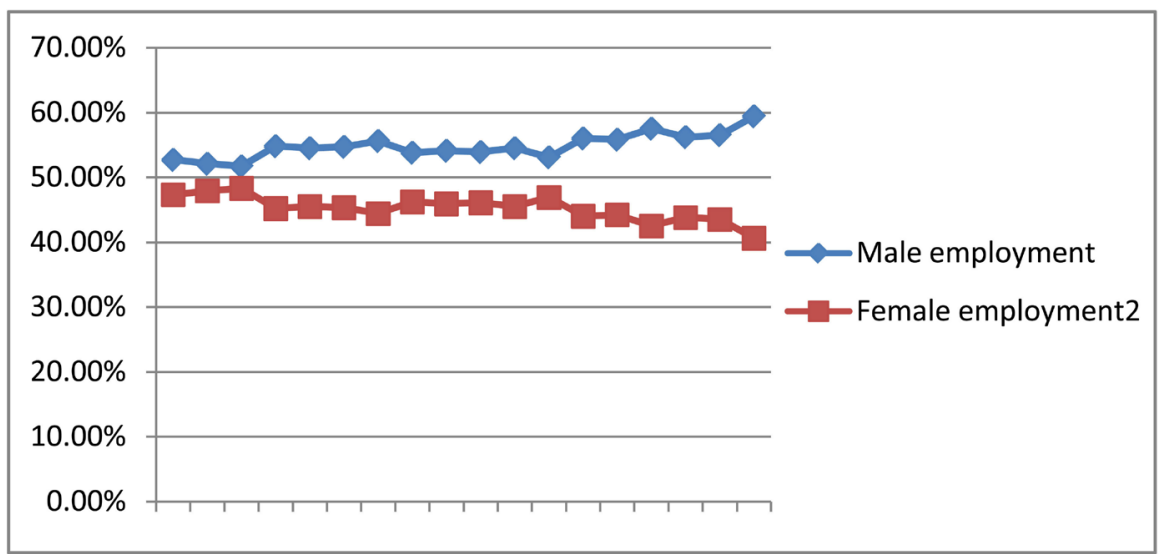

Figure 1. The proportion of male and female employees in Guangdong Province.

Table 2. Education situation of male employees in Guangdong Province.

\begin{tabular}{|c|c|c|c|c|c|c|c|c|c|}
\hline \multirow{2}{*}{ Year } & \multirow{2}{*}{ Illiterate } & \multirow{2}{*}{ Elementary } & \multirow{2}{*}{ Junior } & \multirow{2}{*}{ High } & \multicolumn{5}{|c|}{ College and above } \\
\hline & & & & & Secondary & Vocational & College & Undergraduate & Graduate \\
\hline 1997 & 2.1 & 31 & 43.2 & 17.3 & & & 6.4 & & \\
\hline 1998 & 2.1 & 29.3 & 45.4 & 16.8 & & & 6.4 & & \\
\hline 1999 & 2.4 & 27.2 & 46.8 & 17.4 & & & 6.2 & & \\
\hline 2001 & 1.9 & 25.3 & 50 & 16.7 & - & - & 4.2 & 1.8 & 0.1 \\
\hline 2002 & 1.2 & 20.6 & 50 & 20.2 & - & - & 5.1 & 2.7 & 0.3 \\
\hline 2003 & 1.5 & 21.9 & 49.3 & 19 & - & - & 5.9 & 2.3 & 0.2 \\
\hline 2004 & 1.2 & 20.6 & 51.2 & 19.1 & - & - & 5.7 & 2 & 0.22 \\
\hline 2005 & 1.1 & 18.3 & 51.1 & 21 & - & - & 5.5 & 2.7 & 0.31 \\
\hline 2006 & 1.2 & 18.1 & 52.9 & 19.5 & - & - & 4.9 & 2.9 & 0.39 \\
\hline 2007 & 0.8 & 15.8 & 53.6 & 21.3 & - & - & 5.2 & 3 & 0.38 \\
\hline 2008 & 0.6 & 15.8 & 53 & 21.3 & - & - & 5.5 & 3.5 & 0.35 \\
\hline 2009 & 0.7 & 16.1 & 52.8 & 21.9 & - & - & 5.4 & 2.7 & 0.34 \\
\hline 2010 & 0.4 & 12.8 & 53.6 & 22 & - & - & 6.6 & 4.1 & 0.47 \\
\hline 2011 & 0.5 & 11.6 & 48.2 & 26.3 & - & - & 8.3 & 4.9 & 0.2 \\
\hline 2012 & 0.7 & 11.2 & 48.4 & 27.6 & - & - & 7.7 & 4.2 & 0.23 \\
\hline 2013 & 0.3 & 11.1 & 48.9 & 24.8 & - & - & 9.2 & 5.3 & 0.42 \\
\hline 2014 & 0.3 & 9.4 & 46.9 & 27.2 & - & - & 10.1 & 5.8 & 0.35 \\
\hline 2015 & 0.4 & 10 & 43.5 & 19.4 & 6.8 & 2.4 & 9.8 & 7 & 0.7 \\
\hline
\end{tabular}


Table 3. Education situation of male employees in Guangdong Province.

\begin{tabular}{|c|c|c|c|c|c|c|c|c|c|}
\hline \multirow{2}{*}{ Year } & \multirow{2}{*}{ Illiterate } & \multirow{2}{*}{ Elementary } & \multirow{2}{*}{ Junior } & \multirow{2}{*}{ High } & \multicolumn{5}{|c|}{ College and above } \\
\hline & & & & & Secondary & Vocational & College & Undergraduate & Graduate \\
\hline 1997 & 7.4 & 40.8 & 36 & 12.2 & & & 3.6 & & \\
\hline 1998 & 6.1 & 39.1 & 39.1 & 12 & & & 3.7 & & \\
\hline 1999 & 5.9 & 37.2 & 41.3 & 11.9 & & & 3.7 & & \\
\hline 2001 & 4.8 & 37.5 & 43.2 & 10.1 & - & - & 3.4 & 0.9 & 0.1 \\
\hline 2002 & 4.1 & 32.3 & 44.7 & 12.9 & - & - & 4.4 & 1.4 & 0.2 \\
\hline 2003 & 4.2 & 33.2 & 43.4 & 12.7 & - & - & 5.2 & 1.2 & 0.1 \\
\hline 2004 & 3.1 & 30.8 & 46.6 & 13 & - & - & 4.9 & 1.5 & 0.06 \\
\hline 2005 & 3.8 & 26.8 & 49.3 & 13.7 & - & - & 4.5 & 1.8 & 0.16 \\
\hline 2006 & 3.3 & 28.2 & 48.9 & 13.5 & - & - & 4.2 & 1.7 & 0.22 \\
\hline 2007 & 2 & 25.5 & 51.1 & 13.9 & - & - & 5 & 2.3 & 0.25 \\
\hline 2008 & 2.3 & 24.3 & 50.7 & 14.7 & - & - & 5.3 & 2.6 & 0.25 \\
\hline 2009 & 2.2 & 23.5 & 51.2 & 16 & - & - & 4.6 & 2.1 & 0.3 \\
\hline 2010 & 1.4 & 19.4 & 52.5 & 16.5 & - & - & 6.3 & 3.5 & 0.33 \\
\hline 2011 & 1.1 & 17.2 & 50.9 & 19.4 & - & - & 7.3 & 3.8 & 0.37 \\
\hline 2012 & 1.2 & 18.6 & 48.9 & 19.1 & - & - & 7.8 & 4 & 0.29 \\
\hline 2013 & 1 & 17.8 & 49.9 & 17.9 & - & - & 7.8 & 5.2 & 0.4 \\
\hline 2014 & 0.7 & 16 & 49.1 & 19.9 & - & - & 9.1 & 4.9 & 0.41 \\
\hline 2015 & 1.5 & 16.5 & 41.5 & 14.8 & 6.2 & 2.1 & 9.9 & 6.9 & 0.5 \\
\hline
\end{tabular}

Note: Due to the lack of relevant data in 2000, the data on the education level of male and female employed persons in 2000 is not listed here.

employees accounted for $52 \%$ of the total, and female employees only $48 \%$. After that, the proportion of male employees is on the rise. On the contrary, the proportion of female employees is declining. By 2015, the proportion of male employees has reached $60 \%$, while the proportion of female employees has increased. Then it drops to $40 \%$. The differences between male and female practitioners are growing, and male workers in the labor market are becoming more and more dominant.

As can be seen from Table 2 and Table 3, both male and female employees have a lower proportion of lower education (referring to the education level of junior high school and below), and the degree of higher education (college and The above-mentioned employment staff generally increased, especially in colleges and undergraduates. Compared with the average growth rate, the average annual growth rate of male colleges and above is only $17.62 \%$, but the females reach $33.95 \%$. The most important reason is that the proportion of women in colleges and above in 1997-1999 is lower than that of men.

Comparing the education level of men and women, it can be found that there are obvious differences between male and female employees. The specific performance is that female employees in higher education account for less than male 
employees, but the proportion of lower education is higher than that of males. Female practitioners are less educated than men, especially in higher education.

2.2.4. The Current Situation of Human Capital Stock in Guangdong Province According to the 1998-2016 Labor Yearbook and the 1998-2016 Guangdong Statistical Yearbook, the average annual education years $\mathrm{E}$ and human capital are calculated as shown in Table 4 below.

Among them, due to the lack of relevant data in 2001 in the statistical yearbook, the data for 2000 was obtained by linear interpolation. As can be seen from Table 3 above, the male human capital stock in Guangdong Province has been higher than that of women in the past years. The ratio of male and female human capital stocks is maintained at around $1.1-1.2$, the lowest is 1.07 in 1999 and the highest is 1.4 in 2015. And the proportion has a gradual upward trend.

In addition, the Guangdong Statistical Yearbook data shows that at the end of 2013, the resident population of Guangdong Province was 106.44 million, of which 5,448,200 were men and 5,095,280 were women, with a sex ratio of 1.01 (female is 1). In 2013, the number of women employed in urban units accounted for $41.69 \%$ of the total number of employed people. The target of maintaining the proportion of female employees in urban areas in the Guangdong Women's

Table 4. Average years of education and human capital in each year (Unit: Year).

\begin{tabular}{|c|c|c|c|c|}
\hline Year & $\begin{array}{c}\text { Average years of } \\
\text { education }\end{array}$ & Total human capital & Male human capital & $\begin{array}{c}\text { Female human } \\
\text { capital }\end{array}$ \\
\hline 1997 & 8.4327 & $31,217.01$ & $16,451.37$ & $14,765.65$ \\
\hline 1998 & 8.5077 & $32,192.03$ & $16,772.05$ & $15,419.98$ \\
\hline 1999 & 8.5615 & $32,502.19$ & $16,803.63$ & $15,698.56$ \\
\hline 2000 & 8.5888 & $34,263.56$ & $18,751.98$ & $15,511.58$ \\
\hline 2001 & 8.5980 & $34,896.10$ & $19,479.93$ & $16,067.39$ \\
\hline 2002 & 8.9975 & $37,198.99$ & $21,556.05$ & $17,996.33$ \\
\hline 2003 & 8.9455 & $39,323.79$ & $22,909.37$ & $18,972.48$ \\
\hline 2004 & 9.0585 & $42,410.90$ & $25,298.32$ & $20,202.25$ \\
\hline 2005 & 9.1751 & $46,086.25$ & $25,554.83$ & $21,944.85$ \\
\hline 2006 & 9.1429 & $47,332.98$ & $26,420.71$ & $22,416.09$ \\
\hline 2007 & 9.3313 & $49,843.14$ & $27,520.40$ & $22,322.74$ \\
\hline 2008 & 9.4349 & $51,625.13$ & $29,251.00$ & $22,374.13$ \\
\hline 2009 & 9.3848 & $53,386.56$ & $29,254.53$ & $24,132.03$ \\
\hline 2010 & 9.7634 & $57,315.84$ & $32,590.37$ & $24,725.47$ \\
\hline 2011 & 10.0257 & $59,760.59$ & $33,375.56$ & $26,385.03$ \\
\hline 2012 & 9.993 & $59,617.74$ & $35,152.04$ & $24,465.70$ \\
\hline 2013 & 10.1019 & $61,800.19$ & $35,103.85$ & $26,696.34$ \\
\hline 2014 & 10.2977 & $63,673.05$ & $36,185.19$ & $27,487.86$ \\
\hline 2015 & 10.5375 & $65,535.98$ & $38,928.37$ & $26,607.61$ \\
\hline
\end{tabular}


Development Plan (2011-2020) remained above 42\%.

\section{An Empirical Analysis of the Relationship between Economic Growth and Female Human Capital in Guangdong Province}

\subsection{Research Model}

Discuss the relationship between economic growth and human capital, especially the impact of female human capital on economic growth. Therefore, the model selected in this paper is the Solow model and is based on this model.

\subsubsection{Solow Technology Advancement Model}

$$
Y=F(K, A L)=K^{\alpha}(A L)^{1-\alpha}
$$

Among them, $0<\alpha<1, Y$ means output, $K$ means capital investment, $L$ means labor input, $A$ means technological progress, and is an exogenous variable. Take the logarithm on both sides of model 1 , and the result is

$$
\log Y_{t}=\beta_{0}+\beta_{1} \log K_{t}+\beta_{2} \log L_{t}+\varepsilon_{t}
$$

\section{1) Educational factors}

This paper focuses on the contribution of research human capital to economic growth, and education is a very important factor affecting human capital, especially for women. Therefore, the education factor $G$ is introduced on the basis of model 2 , and the model is re-established.

$$
\log Y_{t}=\beta_{0}+\beta_{1} \log K_{t}+\beta_{2} \log L_{t}+\beta_{3} \log G_{t}+\varepsilon_{t}
$$

\section{2) Human capital factors}

Human capital is an important factor affecting economic development. Ignoring the role of human capital will lead to incorrect conclusions. Therefore, we add human capital factor $\mathrm{H}$ to further study in the study.

$$
Y(t)=K(t)^{\alpha} H(t)^{\beta}(A(t) L(t))^{1-\alpha-\beta}
$$

where $H$ represents the human capital stock, $0<\alpha+\beta<1$. According to the existing literature research method, the measurement of human capital is calculated by multiplying the labor force $L$ by the average education years $E$.

Among them, the average education period $E$ is calculated as

$$
E=\frac{\sum p_{i} \times N_{i}}{P}
$$

where $p$ indicates the number of people in each education class, and $N$ indicates the years of education of each education class. See Table 1 above for details.

\subsubsection{Solow Technology Advancement Model}

To correct multi-collinearity and eliminate economies of scale, take the variable to the average labor force.

$$
\frac{Y}{L}=A(t)\left(\frac{K}{L}\right)^{\alpha}
$$

Logarithm on both sides: 


$$
\log \frac{Y_{t}}{L_{t}}=\beta_{0}+\beta_{1} \log \frac{K_{t}}{L_{t}}+\varepsilon_{t}
$$

In the same way, adding the education factor $G$ is expressed as:

$$
\frac{Y}{L}=a^{\beta_{0}}\left(\frac{K}{L}\right)^{\beta_{1}} G^{\beta_{2}} e^{\varepsilon}
$$

Logarithm on both sides

$$
\log \frac{Y_{t}}{L_{t}}=\beta_{0}+\beta_{1} \log \frac{K_{t}}{L_{t}}+\beta_{1} \log G+\varepsilon_{t}
$$

Similarly, for model, the average model of the labor force is

$$
\begin{gathered}
Y(t)=K(t)^{\alpha} H(t)^{\beta}(A(t) L(t))^{1-\alpha-\beta} \\
\frac{Y}{L}=a^{\beta_{0}}\left(\frac{K}{L}\right)^{\beta_{1}} E^{\beta_{2}} e^{\epsilon}
\end{gathered}
$$

Among them, $\beta_{0}=1-\alpha-\beta$, on this basis continue to introduce the education factor $G$, get

$$
\frac{Y}{L}=a^{\beta_{0}}\left(\frac{K}{L}\right)^{\beta_{1}} E^{\beta_{2}} G^{\beta_{3}} E^{\epsilon}
$$

Take logarithm on both sides

$$
\log \frac{Y_{t}}{L_{t}}=\beta_{0}+\beta_{1} \log \frac{K_{t}}{L_{t}}+\beta_{2} \log E_{t}+\beta_{3} \log G_{t}+\epsilon_{t}
$$

In addition, this article made a modification:

$$
\log \frac{Y_{t}}{H_{t}}=\beta_{0}+\beta_{1} \log \frac{K_{t}}{H_{t}}+\beta_{2} \log H_{t}+\beta_{3} \log E_{t}+\epsilon_{t}
$$

\subsection{Data Selection}

\subsubsection{Output $Y$}

The output is expressed in terms of the annual GDP of Guangdong Province. The data is taken from 1997 to 2015 . In order to eliminate the impact of price factors, the annual real GDP is obtained, and the actual production per year is calculated according to the Guangdong GDP Index $(1978=100)$. Total value. The data comes from the wind database.

\subsubsection{Capital Stock $K$}

Capital stock The basic data used here is the annual total fixed assets of Guangdong Province, rather than the fixed assets investment. In order to eliminate the price factor, the 1978 price index $=100$ is used for deflation. In addition, in order to eliminate the impact of capital depreciation, the annual capital stock calculation formula is

$$
K_{t}=K_{t-1}(1-\gamma)+\Delta K
$$

Among them, $\gamma$ represents the depreciation rate of capital. Here, for the convenience of discussion, the annual GDP growth rate is adopted. The data comes 
from the wind database

\subsubsection{Labor Input $L$}

Labor input. The data used here is the annual data of practitioners in Guangdong Province. The data comes from the China Statistical Yearbook and the China Labor Yearbook.

\subsubsection{Educational Factor $G$}

For the measurement of educational factors, the data uses the total expenditure of each practitioner in education. The education includes macro-level national education and skills training for each practitioner to improve their skills. Based on the principle of data availability, this paper uniformly adopts the annual financial expenditure of the Guangdong Provincial Government on education. Although private education will also generate expenditures, it will also affect the human capital stock. However, considering that this part is small, and this part of the data is difficult to obtain, it is only measured by the Guangdong provincial government's financial expenditure data.

\subsubsection{Human Capital Stock}

According to the existing literature research method, the measurement of human capital is calculated by multiplying the labor force $L$ by the average education years $E$. The calculation method is as described in the model introduction.

\subsection{Variable Description}

According to the above data selection, this paper describes all statistical variables. Table 5 and Table 6 below list the variables and basic statistics.

\section{The Results Analysis and Main Conclusions}

\subsection{Empirical Study on the Contribution of Human Capital to the Economic Growth of Guangdong Province}

The empirical regression results are as Table 7.

Table 5. Variables and descriptions.

\begin{tabular}{|c|c|}
\hline Variable & Variable description \\
\hline $\log (Y)$ & The logarithm of actual GDP in Guangdong Province over the years \\
\hline $\log (K)$ & The logarithm of capital stock in Guangdong Province over the years \\
\hline $\log (L)$ & The logarithm of the labor force in Guangdong Province over the years \\
\hline$E$ & Average length of education for the labor force \\
\hline$G$ & Annual financial expenditure of the Guangdong Provincial Government \\
\hline $\log (H)$ & The logarithm of human capital stock in Guangdong Province over the years \\
\hline $\log (Y / L)$ & The logarithm of the average labor force of Guangdong Province over the years \\
\hline $\log (K / L)$ & $\begin{array}{l}\text { The logarithm of the average capital stock of labor force in Guangdong Province } \\
\text { over the years }\end{array}$ \\
\hline
\end{tabular}


Table 6. Statistical variables for each variable.

\begin{tabular}{cccccc}
\hline Variable & Number of observations & Mean & Variance & Minimum & Maximum \\
\hline $\log (Y)$ & 19 & 5.5313 & 0.3195 & 4.6449 & 6.3432 \\
$\log (K)$ & 19 & 4.9741 & 0.3821 & 4.0701 & 5.9363 \\
$\log (L)$ & 19 & 3.6943 & 0.0068 & 3.5684 & 3.6943 \\
$\log (E)$ & 19 & 0.9679 & 0.0009 & 0.9260 & 1.0227 \\
$\log (G)$ & 19 & 3.7935 & 0.4489 & 2.8478 & 4.7908 \\
$\log (H)$ & 19 & 4.6622 & 0.0124 & 4.4944 & 4.8165 \\
$\log (Y / L)$ & 19 & 5.8369 & 0.2341 & 5.0765 & 6.5495 \\
$\log (K / L)$ & 19 & 1.2798 & 0.2887 & 0.5016 & 2.1426 \\
\hline
\end{tabular}

Note: The data comes from the China Statistical Yearbook, the China Labor Yearbook and the wind database. Among them, since the 2001 China Labor Yearbook did not collect detailed data on the education level of the relevant employed persons, the data for 2000 is to use the linear interpolation method to estimate the average years of education in the year and calculate the relevant Human capital stock and other data.

Table 7. Regression results of economic growth in Guangdong Province.

\begin{tabular}{ccccc}
\hline \multicolumn{5}{c}{ Dependent variable: $\ln Y$} \\
\hline Independent Variable & $(1)$ & $(2)$ & $(3)$ & $(4)$ \\
\hline $\ln K$ & $0.648285^{* * *}$ & $0.4747132^{* * *}$ & $0.4664918^{* * *}$ & $0.4960292^{* * *}$ \\
& $(0.000)$ & $(0.000)$ & $(0.025)$ & $(0.001)$ \\
$\ln H$ & --- & $2.443399^{* * *}$ & --- & 2.058361 \\
& --- & $(0.000)$ & --- & $(0.171)$ \\
$\ln L$ & $2.013501^{* * *}$ & --- & --- & 0.3633671 \\
& $(0.001)$ & --- & --- & $(0.774)$ \\
$\ln G$ & --- & --- & $0.4122285^{* *}$ & -- \\
& --- & --- & $(0.030)$ & -- \\
$\operatorname{Intercept}$ & $-11.82659^{* * *}$ & $-18.93119^{* * *}$ & $3.79258^{* * *}$ & $-18.13285^{* * *}$ \\
& $(0.004)$ & $(0.001)$ & $(0.000)$ & $(0.005)$ \\
$R^{2}$ & 0.9975 & 0.9978 & 0.9963 & 0.9978 \\
\hline
\end{tabular}

Note: ${ }^{*}$ indicates significant at the significance level of $0.1,{ }^{* *}$ indicates significant at the 0.05 significance level, ${ }^{*}$ indicates significant at the significance level of 0.01 , and standard error for the parentheses.

In Table 7, the regression results of each model are significant, and the regression coefficients are all above $99 \%$, indicating that the model has a good fitting effect. The regression results of the model (1) in Table 7 show that the elasticity coefficient of the labor variable is 2.0136 , and the significance level is $1 \%$. That is, if the other conditions remain unchanged, the GDP of Guangdong Province will increase 2.0136 percentage points correspondingly for every one percentage point increase in Guangdong labor force. The regression results of model (2) show that the elasticity coefficient of human capital variable is 2.4434, and the significance level is $1 \%$. That is, if other conditions remain unchanged, the GDP of Guangdong Province will increase by 2.4434 percentage points for 
each percentage point increase of human capital in Guangdong Province. The model (3) regression results show that the elasticity coefficient of the education input variable is 0.4122 , and the significance level is $5 \%$. That is, if other conditions remain unchanged, the Guangdong GDP will increase by 0.4122 percentage points for each additional percentage point of Guangdong education investment.

The regression results of model (4) show that after adding the two variables of human capital and labor, the regression becomes insignificant, which is also because the calculation of human capital uses the product of labor and average years of education. This results in a certain degree of multicollinearity in the model (4), which also confirms what we said in the above model. Therefore, further modifications are made to this model in this paper. The regression results are shown in Table 8.

According to Table 7 and Table 8, the coefficient of elasticity of material capital is 0.475 , the coefficient of elasticity of human capital reaches 1.415 , and the coefficient of elasticity of human capital is much higher than that of physical

Table 8. Regression results of labor average.

\begin{tabular}{|c|c|c|c|c|}
\hline \multicolumn{5}{|c|}{ Dependent variable: $\ln (Y / L)$} \\
\hline Independent Variable & (5) & $(6)$ & (7) & (8) \\
\hline \multirow{2}{*}{$\ln (K / L)$} & $0.8974833^{\star * *}$ & $0.5045806^{\star * \star}$ & $0.9135866^{* * *}$ & $0.4960374^{* * *}$ \\
\hline & $(0.000)$ & $(0.000)$ & $(0.000)$ & $(0.001)$ \\
\hline \multirow{2}{*}{$\ln H$} & --- & $1.913992^{\star * *}$ & --- & $1.917754^{\star \star *}$ \\
\hline & -- & $(0.000)$ & --- & $(0.001)$ \\
\hline \multirow[b]{2}{*}{$\ln E$} & --- & --- & -0.2910872 & 0.1404669 \\
\hline & --- & --- & 0.879 & $(0.917)$ \\
\hline \multirow{2}{*}{ Intercept } & $10.79533^{* * *}$ & $-8.593914^{*}$ & $11.39663^{* *}$ & -8.922193 \\
\hline & $(0.000)$ & $(0.072)$ & $(0.010)$ & $(0.128)$ \\
\hline$R^{2}$ & 0.9935 & 0.9970 & 0.9935 & 0.9970 \\
\hline \multicolumn{5}{|c|}{ Dependent variable: $\ln (Y / H)$} \\
\hline Independent Variable & \multicolumn{2}{|c|}{ (9) } & \multicolumn{2}{|c|}{ (10) } \\
\hline \multirow{2}{*}{$\ln (K / H)$} & \multicolumn{2}{|c|}{$0.4747132^{* * *}$} & \multicolumn{2}{|c|}{0.11975} \\
\hline & \multicolumn{2}{|c|}{$(0.000)$} & \multicolumn{2}{|c|}{$(0.369)$} \\
\hline \multirow{2}{*}{$\ln H$} & \multicolumn{2}{|c|}{$1.918112^{\star * *}$} & \multicolumn{2}{|c|}{$1.414589^{* * *}$} \\
\hline & \multicolumn{2}{|c|}{0.001} & \multicolumn{2}{|c|}{$(0.002)$} \\
\hline \multirow{2}{*}{$\ln G$} & \multicolumn{2}{|c|}{---} & \multicolumn{2}{|c|}{$0.353^{* * *}$} \\
\hline & \multicolumn{2}{|c|}{---} & \multicolumn{2}{|c|}{$(0.004)$} \\
\hline \multirow{2}{*}{ Intercept } & \multicolumn{2}{|c|}{$-18.93119^{* * *}$} & \multicolumn{2}{|c|}{$-16.35427^{* * *}$} \\
\hline & \multicolumn{2}{|c|}{$(0.001)$} & \multicolumn{2}{|c|}{$(0.001)$} \\
\hline$R^{2}$ & \multicolumn{2}{|c|}{0.9966} & \multicolumn{2}{|c|}{0.9935} \\
\hline
\end{tabular}

Note: ${ }^{*}$ indicates significant at the significance level of $0.1,{ }^{* *}$ indicates significant at the 0.05 significance level, ${ }^{*}$ indicates significant at the significance level of 0.01 , and standard error for the parentheses. 
capital, indicating that the current economic development of Guangdong Province has entered a human capital-driven type rather than a simple investment-driven type.

Based on the above regression results, we calculate the contribution rate of a production factor to the economic growth of Guangdong Province as shown in Table 9 below.

It can be seen from Table 9 that the contribution rate of material capital to economic growth in Guangdong is $37.38 \%$, the contribution rate of human capital to economic growth is $17.04 \%$, and the contribution rate of labor to capital is also $16.51 \%$. The contribution rate of education expenditure is $29.07 \%$

\subsection{Empirical Study on the Contribution of Human Capital to the Economic Growth of Guangdong Province}

Based on the available data, this paper calculates the growth rate of human capital at all levels of men and women. The calculation formula is:

$$
\begin{gathered}
\gamma=\frac{g_{i} * R_{i}}{g_{H}} \\
\delta=\gamma * D_{H}
\end{gathered}
$$

Note: $\gamma$ indicates the contribution rate of human capital generated by education at all levels to the growth rate of total human capital. $g_{i}$ indicates the growth rate of human capital generated by education at all levels, and $R_{i}$ indicates the proportion of human capital generated by education at all levels to total human capital. $\Delta_{i}$ represents the contribution rate of human capital generated by education at all levels to overall economic growth. The results obtained are shown in Table 10 and Table 11.

It can be seen from Table 10 and Table 11 that illiteracy and primary education have a negative contribution to economic growth (the contribution rate of male primary education is 0 because two decimals are retained when the results are displayed). Economic growth has a reverse effect, which is consistent with

\begin{tabular}{|c|c|c|c|c|c|}
\hline \multirow[t]{2}{*}{ Variable } & $\begin{array}{c}\text { Elastic } \\
\text { coefficient }\end{array}$ & $\begin{array}{l}\text { Average annual } \\
\text { growth (\%) }\end{array}$ & $\begin{array}{l}\text { Factor growth } \\
\text { share }(\%)\end{array}$ & $\begin{array}{c}\text { Factor contribution } \\
\text { rate }(\%)\end{array}$ & \multirow{2}{*}{$\begin{array}{c}\text { Contribution } \\
\text { rate adjustment } \\
(\%)\end{array}$} \\
\hline & $(A)$ & (B) & $\left(C=A^{\star} B\right)$ & $(D=C / 13.62)$ & \\
\hline K & 0.475 & 27.64 & 13.129 & 96.40 & 37.38 \\
\hline $\mathrm{H}$ & 1.415 & 4.23 & 5.98545 & 43.95 & 17.04 \\
\hline $\mathrm{L}$ & 2.014 & 2.88 & 5.80032 & 42.59 & 16.51 \\
\hline G & 0.353 & 28.93 & 10.21229 & 74.98 & 29.07 \\
\hline GDP & --- & 13.62 & --- & --- & --- \\
\hline Constant & \multicolumn{4}{|c|}{-16.354} & --- \\
\hline
\end{tabular}

Table 9. Contribution rate of various production factors to economic growth in Guangdong.

Note: In order to ensure a total contribution rate of $100 \%$, the factor contribution rate in Table 9 is standardized. 
Table 10. Human capital situation of male employees at all levels of education.

\begin{tabular}{|c|c|c|c|c|c|c|c|}
\hline Education level & Illiteracy & Elementary & Junior & High & College & Undergraduate & Graduate \\
\hline $\begin{array}{l}\text { Average growth } \\
\text { rate }\end{array}$ & $-0.06 \%$ & $-1.23 \%$ & $5.47 \%$ & $6.66 \%$ & $19.45 \%$ & $18.53 \%$ & $35.38 \%$ \\
\hline Average ratio & $1.08 \%$ & $18.12 \%$ & $49.38 \%$ & $21.04 \%$ & $7.22 \%$ & $3.66 \%$ & $0.33 \%$ \\
\hline $\begin{array}{l}\text { Contribution } \\
\text { rate to } \mathrm{H}\end{array}$ & $-0.02 \%$ & $-5.27 \%$ & $63.86 \%$ & $33.13 \%$ & $33.20 \%$ & $16.03 \%$ & $2.76 \%$ \\
\hline $\begin{array}{l}\text { Contribution } \\
\text { rate to GDP }\end{array}$ & $0.00 \%$ & $-0.90 \%$ & $10.88 \%$ & $5.64 \%$ & $5.66 \%$ & $2.73 \%$ & $0.47 \%$ \\
\hline
\end{tabular}

Table 11. Human capital situation of female employees at all levels of education.

\begin{tabular}{cccccccc}
\hline Education level & Illiteracy & Elementary & Junior & High & College & Undergraduate & Graduate \\
\hline $\begin{array}{c}\text { Average growth } \\
\text { rate }\end{array}$ & $-1.68 \%$ & $-1.65 \%$ & $4.79 \%$ & $7.57 \%$ & $14.52 \%$ & $22.79 \%$ & $28.05 \%$ \\
$\begin{array}{c}\text { Average ratio } \\
\begin{array}{c}\text { Contribution } \\
\text { rate to H }\end{array}\end{array}$ & $-1.12 \%$ & $26.92 \%$ & $46.57 \%$ & $15.02 \%$ & $6.12 \%$ & $2.92 \%$ & $0.26 \%$ \\
$\begin{array}{c}\text { Contribution } \\
\text { rate to GDP }\end{array}$ & $-0.21 \%$ & $-10.50 \%$ & $52.74 \%$ & $26.88 \%$ & $21.01 \%$ & $15.73 \%$ & $1.72 \%$ \\
\hline
\end{tabular}

the current economic development. Inferior education and even uneducated practitioners will hinder economic growth; junior high school and high school education have a high contribution rate to economic development. Especially in junior high school (male contribution rate reached $10.88 \%$, women also reached $8.99 \%$ ), but the contribution rate of higher education (such as undergraduate and postgraduate) is even lower (male practitioners graduate contribution rate is $0.47 \%$, female). It is only $0.29 \%$, and the economic growth rate of higher education is far higher than the level of general education. The reason is that the number of employees in higher education is very small, and the proportion of total human capital is low when calculating human capital, for example. The average proportion of male graduates in human capital is only $0.33 \%$, and that of females is only $0.26 \%$, but this part is also included in the calculation of contribution rate. Factors have been taken into consideration, which has led to a lower contribution rate of higher education.

\subsection{Analysis of the Growth Rate of Education at All Levels}

According to the above calculation method, this paper calculates the contribution rate of economic development at all levels of education for men and women to the following table. In this calculation, considering the lack of data in 2000 and the three years of 1997, 1998 and 1999, there is no distinction between junior college, undergraduate and postgraduate statistics, so only the situation in 2002-2015 will be discussed here.

Table 12 shows that the highest average value of male employees' contribution is college, which is $11.99 \%$, followed by undergraduate and postgraduate 
Table 12. Contribution rate of educational attainment levels of male employees at all levels.

\begin{tabular}{cccccccc}
\hline \multirow{2}{*}{ Year } & Illiteracy & Elementary & Junior & High & College & Undergraduate & Graduate \\
\cline { 2 - 7 } & \multicolumn{7}{c}{ Contribution rate } \\
\hline 2002 & $-0.93 \%$ & $-5.26 \%$ & $13.75 \%$ & $17.64 \%$ & $4.52 \%$ & $4.60 \%$ & $1.80 \%$ \\
2003 & $1.47 \%$ & $8.47 \%$ & $7.04 \%$ & $-0.02 \%$ & $4.04 \%$ & $-0.65 \%$ & $-0.17 \%$ \\
2004 & $-0.30 \%$ & $1.73 \%$ & $16.32 \%$ & $4.56 \%$ & $0.83 \%$ & $-0.17 \%$ & $0.10 \%$ \\
2005 & $-0.16 \%$ & $-3.69 \%$ & $0.82 \%$ & $4.57 \%$ & $-0.27 \%$ & $1.93 \%$ & $0.26 \%$ \\
2006 & $0.97 \%$ & $2.58 \%$ & $23.45 \%$ & $-4.91 \%$ & $-2.44 \%$ & $2.02 \%$ & $0.74 \%$ \\
2007 & $-0.78 \%$ & $-4.60 \%$ & $9.53 \%$ & $9.42 \%$ & $1.76 \%$ & $0.75 \%$ & $0.02 \%$ \\
2008 & $-0.58 \%$ & $4.73 \%$ & $12.87 \%$ & $6.38 \%$ & $3.25 \%$ & $4.00 \%$ & $-0.04 \%$ \\
2009 & $0.58 \%$ & $1.54 \%$ & $-0.96 \%$ & $3.10 \%$ & $-0.49 \%$ & $-3.08 \%$ & $-0.05 \%$ \\
2010 & $-0.34 \%$ & $-3.39 \%$ & $16.25 \%$ & $6.07 \%$ & $5.53 \%$ & $6.57 \%$ & $0.59 \%$ \\
2011 & $0.56 \%$ & $-3.33 \%$ & $-15.23 \%$ & $23.56 \%$ & $9.55 \%$ & $4.38 \%$ & $-0.45 \%$ \\
2012 & $-23.67 \%$ & $-13.50 \%$ & $-198.66 \%$ & $-207.09 \%$ & $12.57 \%$ & $29.10 \%$ & $-3.46 \%$ \\
2013 & $-0.80 \%$ & $-0.53 \%$ & $2.04 \%$ & $-11.85 \%$ & $8.27 \%$ & $6.42 \%$ & $1.61 \%$ \\
2014 & $0.05 \%$ & $-6.71 \%$ & $-2.99 \%$ & $19.96 \%$ & $7.47 \%$ & $4.17 \%$ & $-0.28 \%$ \\
2015 & $1.01 \%$ & $8.41 \%$ & $-0.55 \%$ & $-26.29 \%$ & $113.29 \%$ & $12.16 \%$ & $4.69 \%$ \\
Mean & $-1.64 \%$ & $-0.97 \%$ & $-8.31 \%$ & $-11.06 \%$ & $11.99 \%$ & $5.16 \%$ & $0.38 \%$ \\
\hline & & & & & & & \\
\hline
\end{tabular}

students, which are $5.16 \%$ and $0.38 \%$ respectively; and the contribution rate of illiteracy, elementary school, junior high school and high school The average is negative.

Table 13 shows that the highest average value of female employees' contribution is junior high school, reaching 33.05\%, followed by high school, reaching $14.52 \%$, junior college and undergraduate also $4.40 \%$ and $3.28 \%$, and graduate students also have an average of $0.70 \%$. Value; unlike men, except for primary schools, which are negative, others are positive.

Comparing Table 12 and Table 13 shows that both male and female employees are higher in higher education (high school and above) than in lower education (below high school); female employees (in addition to junior college and undergraduate) are generally higher than men, and the contribution of graduate students is 0.22 percentage points higher than that of men.

\section{Policy and Recommendations}

From the above empirical results, this article puts forward some policy opinions:

1) The government continues to strengthen fiscal spending on education. Government spending on education reflects the government's emphasis on education and the ability to develop education. The empirical results of this paper show that the government has a positive effect on economic development in terms of education expenditure, and the contribution rate has reached $29.07 \%$.

2) The government continues to strengthen the popularization of education, 
Table 13. Contribution rate of male employees at all levels of education at all levels.

\begin{tabular}{lccccccc}
\hline \multirow{2}{*}{ Year } & Illiteracy & Elementary & Junior & High & College & Undergraduate & Graduate \\
\cline { 2 - 7 } & \multicolumn{7}{c}{ Contribution rate } \\
\hline 2002 & $-0.46 \%$ & $-2.94 \%$ & $18.35 \%$ & $14.34 \%$ & $5.11 \%$ & $2.68 \%$ & $0.64 \%$ \\
2003 & $1.00 \%$ & $8.28 \%$ & $3.05 \%$ & $1.44 \%$ & $3.81 \%$ & $-0.34 \%$ & $-0.14 \%$ \\
2004 & $-1.44 \%$ & $-0.81 \%$ & $14.50 \%$ & $2.54 \%$ & $0.04 \%$ & $1.08 \%$ & $-0.05 \%$ \\
2005 & $2.48 \%$ & $-2.89 \%$ & $14.45 \%$ & $3.90 \%$ & $-0.02 \%$ & $1.07 \%$ & $0.60 \%$ \\
2006 & $-2.35 \%$ & $13.29 \%$ & $4.06 \%$ & $0.56 \%$ & $-1.23 \%$ & $-0.38 \%$ & $0.56 \%$ \\
2007 & $-2.55 \%$ & $-8.15 \%$ & $6.67 \%$ & $1.13 \%$ & $2.98 \%$ & $2.57 \%$ & $0.11 \%$ \\
2008 & $1.67 \%$ & $-5.19 \%$ & $-1.34 \%$ & $4.20 \%$ & $1.57 \%$ & $1.65 \%$ & $0.00 \%$ \\
2009 & $0.35 \%$ & $5.06 \%$ & $22.83 \%$ & $13.91 \%$ & $-1.47 \%$ & $-1.35 \%$ & $0.44 \%$ \\
2010 & $-1.13 \%$ & $-6.93 \%$ & $6.16 \%$ & $2.16 \%$ & $5.89 \%$ & $5.74 \%$ & $0.10 \%$ \\
2011 & $-0.71 \%$ & $-3.70 \%$ & $7.03 \%$ & $19.72 \%$ & $6.89 \%$ & $2.41 \%$ & $0.29 \%$ \\
2012 & $-0.99 \%$ & $-3.63 \%$ & $380.99 \%$ & $118.70 \%$ & $5.14 \%$ & $6.83 \%$ & $5.65 \%$ \\
2013 & $-0.42 \%$ & $3.67 \%$ & $26.36 \%$ & $1.88 \%$ & $3.31 \%$ & $10.13 \%$ & $0.94 \%$ \\
2014 & $-1.10 \%$ & $-6.69 \%$ & $3.62 \%$ & $16.17 \%$ & $10.29 \%$ & $-0.82 \%$ & $0.13 \%$ \\
2015 & $9.39 \%$ & $-0.17 \%$ & $-44.00 \%$ & $2.63 \%$ & $19.34 \%$ & $14.61 \%$ & $0.53 \%$ \\
Mean & $0.27 \%$ & $-0.77 \%$ & $33.05 \%$ & $14.52 \%$ & $4.40 \%$ & $3.28 \%$ & $0.70 \%$ \\
\hline & & & & & & & \\
\hline
\end{tabular}

especially in higher education and above. The empirical results of this paper find that the education level below high school has hindered the development of the economy with the development of the times (the contribution rate is generally negative), while the contribution rate of higher education is positive but not very high, indicating that higher education is promoting Economic development needs to continue to strengthen, especially for graduate students and above.

3) Strengthen the education of women. The empirical results of this paper find that female employees at all levels have a certain degree of positive promotion to economic development (compared to males), but the problem is that women are generally less educated than men, indicating that women's education should be more popular. In strength, the government should continue to actively promote the equal access of women and men to education, and actively strengthen the education of women.

4) Promote equality between men and women in employment. The data in this paper show that there is a certain gap between the number of male and female employed persons, and this gap has an expanding trend, indicating that there is still some gender discrimination in social employment, so it is necessary to promote equal employment between men and women.

Finally, the shortcoming of this paper is that it only analyzes the data of Guangdong Province in a macroscopic way, and does not analyze the details of each prefecture-level city. The main reason is the difficulty of data acquisition. 
Therefore, the next step is to work hard to continue to improve in this area.

\section{Conflicts of Interest}

The author declares no conflicts of interest regarding the publication of this paper.

\section{References}

[1] Schultz, T.W. (1990) Human Capital Investment: The Role of Education and Research. Jiang, B. and Zhang, Y., Trans. The Commercial Press, Beijing, 152-153.

[2] Pan, J.X. (2003) Gender Human Capital Theory. Journal of Renmin University of China, 3.

[3] Sun, J., Yan, H. and Wang, D. (2006) An Empirical Analysis of the Economic Growth Gap in Eastern and Central and Western China-Based on the Perspective of Female Human Capital. Journal of Ocean University of China (Social Science Edition), No. 2, 35-41.

[4] Wei, J.F., Li, L.T. and Su, Z.W. (2006) Analysis on the Gender Gap of Rural Human Capital, Its Causes and Countermeasures. Rural Economy, No. 3, 105-106.

[5] Guo, Q.W. and Jia, J.X. (2009) Public Education Policy, Economic Growth and Human Capital Premium. Economic Research, No. 10, 22-35.

[6] Zhang, Y. (2009) Research on Regional Economic Growth Difference Based on Female Human Capital. Northwest University, Chongqing.

[7] Sun, J.L., Gu, H. and Ma, C. (2014) Human Capital Investment and Economic Growth-Based on the Analysis of Provincial Panel Data from 1997 to 2010 in China. Soft Science, 28, 1-6.

[8] Hu, Z.J. (2016) Research on the Correlation between Human Capital and Regional Economic Growth-Based on Gender Differences. China Collective Economy, No. $10,56-57$.

[9] Graham, J.W. and Webb, R.H. (1979) Stocks and Depreciation of Human Capital: New Evidence from a Present-value Perspective. Review of Income and Wealth, 25, 209-224. https://doi.org/10.1111/j.1475-4991.1979.tb00094.x

[10] Hou, F.F., Fan, Y.B. and Sun, G.L. (2005) Re-Estimation of China's Human Capital Stock: 1995-2005. Nanda Business Review, No. 3, 27-54.

[11] Qian, X.Y., Wang, Q.S. and Liu, H. (2008) Re-Estimation of China's Human Capital Level: 1995-2005. Statistical Research, 12, 3-10. 